which may leave permanent neurological abnormalities. These have been documented in $\mathbf{8 9 8}$ former prisoners of war in the Far East. ${ }^{3}$ Malnutrition may be associated with several different neurological syndromes, although the exact aetiology remains to be established. Under such circumstances multiple deficiencies are common. Experimentally induced deficiency of a single dietary constituent does not produce exactly the same disease as that associated with malnutrition. Peripheral neuropathy, with or without symptoms such as burning feet, amblyopia, or deafness, was the commonest manifestation of nutritional neuropathy.

The incidence of residual optic atrophy and deafness was surprisingly low $(4 \%)$, and residual symptomatic peripheral neuropathy was seen in nearly as many $(3 \%)$, half of whom had persistent "burning feet." Abnormal neurological signs without symptoms were found in a similar number. Although there have been few detailed pathological studies of patients with a history of nutritional neuropathy, extensive degeneration of the distal ends of fibres in the posterior columns has been found. ${ }^{4}$ Thus persistent neuropathy is likely to be due to central distal axonopathy. The degree of peripheral axonopathy has not been assessed.

These former prisoners of war are reaching an age when the common degenerative changes of old age are likely to occur. Probably these will be more severe than in their contemporaries, since their neurological reserve may be less. For example, cervical spondylosis causing damage to posterior column fibres will produce a much greater clinical deficit if a proportion of these fibres have already degenerated. The possibility of previous neuronal damage must be taken into account when seeking the cause of apparently new neurological problems in former prisoners of war.

Pamela M Le Quesne

Consultant Neurologist,

Middlesex Hospital,

London WIN 8AA

: Spencer PS, Schaumburg HH. Central-peripheral distal axonopathythe pathology of dying-back polyneuropathies. Progress in Neuropathology 1977;3:253-95.

${ }^{2}$ Schaumburg HH, Spencer PS, Krinke G, Thomann P, Hess R. The CNS distal axonopathy in dogs intoxicated with clioquinol. $\mathcal{F}$ Neuropathol Exp Neurol 1978;37:686a.

${ }^{3}$ Gill GV, Bell DR. Persisting nutritional neuropathy amongst former war prisoners. F Neurol Neurosurg Psychiatry 1982;45:861-5.

4 Victor M. Polyneuropathy due to nutritional deficiency and alcoholism. In: Dyck PJ, Thomas PK, Lambert EH, eds. Peripheral neuropathy. Philadelphia: Saunders Co, 1975:1030-66.

\section{Interictal behaviour in temporal lobe epilepsy}

Over the years our concepts of the types and frequency of interictal psychopathology associated with epilepsy have changed. ${ }^{2}$ In the last century the dominant view was that both the intellect and the personality deteriorated on a genetic basis-a concept influenced by Morel's degeneracy theory of mental disorder. ${ }^{2} 3$ At the turn of the century the concept of the "epileptic personality" gradually gained ascendency, only to recede with the studies of Lennox ${ }^{4}$ showing that most epileptic patients were normal mentally. These findings have been confirmed by modern epidemiological studies which suggest that only one third of patients have recognisable interictal psychological disorders, ${ }^{5}$ a pre valence similar to that in patients with other chronic cerebra 5 disorders. ${ }^{6}$

In 1948 Gibbs et $a l^{7}$ reported that patients with psychomotor seizures had a significantly higher incidence of psychopathology than patients with other types of seizure, and we thus entered the era of "psychomotor peculiarity." This view implies that patients with psychomotor seizures or temporaf lobe epilepsy are particularly susceptible to personality of psychiatric disorders of various types. The concept has been fuelled by a wealth of experimental evidence showing the? importance of the limbic system and temporal lobes in the emotional and behavioural life of animals ${ }^{8}$ and man. There is also much interest in some of the overlapping psychopathological manifestations of "complex partial seizures" an some psychiatric disorders such as schizophrenia in which the limbic system has also been implicated. ${ }^{9}$

In the last 35 years an enormous and largely conflicting number of publications have accumulated on this subject. ${ }^{91}$ With notable exceptions the main proponents of the concept have been psychiatrists, while neurologists have been mor sceptical. Stevens ${ }^{11}$ recently summarised nine controlle studies, including three of her own, using either objective o£ projective psychological tests or blind psychiatric interviews which failed to show any increase in psychopathology in patients with temporal lobe epilepsy compared with matchedo patients with generalised seizures or focal non-limbic epilepsy? or control populations.

The latest entrants to the debate have been Bear and Fedio, ${ }^{12}$ who concluded that everyone was using the wrongs tools for the task, and devised their own scale of rating behaviour and personality, based on clinical observation. Theyo showed that 27 outpatients with temporal lobe epilepsy had a different personality profile from patients with neurologicab disease and normal controls (as well as showing differences between right and left sided temporal lobe epilepsy). Recently Bear et al ${ }^{13}$ reported that 10 hospital inpatients with tempora lobe epilepsy had a significantly different personality profile from 10 matched patients with generalised or focal non-tempora $\overrightarrow{\vec{p}}$ lobe epilepsy. The former were characterised in particular by circumstantiality, deepened affects, and an interest in religiont and philosophy. This study was undertaken in a psychiatric hospital, but surprisingly the authors do not give the psychiatrie diagnosis in their epileptic groups, even though they implys that the reasons for admission in two such groups are usually. different. Mungas ${ }^{14}$ showed that a large percentage of the variation in character traits on the Bear and Fedio rating scale can be accounted for by the presence or absence of psychiatrie illness in a neurological clinic. Hermann and Riel ${ }^{15}$ compared心 14 matched patients with temporal or generalised epilepsy. Thes former showed important differences only in four of the $1 \$$ traits on the Bear and Fedio rating scale-increased sense of personal destiny, dependence, paranoia, and philosophica interest. Some of the trends were in the opposite direction too those predicted. These inconclusive data are illustrative of the conflicting literature on temporal lobe epilepsy and behaviour

It is surprising to a neurologist that striking differences in ${ }^{2}$ personality should be expected to be shown in studies of such relatively small numbers of patients. After all, temporal lobe⿳亠丷厂巾 epilepsy is very common. In a retrospective study of $66 \hat{\frac{0}{0}}$ patients with temporal lobe epilepsy recruited from all the departments of a district general hospital $57 \%$ were mentally normal and only $6 \%$ had severe psychological disorders. ${ }^{16}$ 응

What reasons are there for the continuing controversy in this difficult subject ? Firstly, the terminology is confusing due 
to a looseness or absence of definition of terms. Psychomotor seizures evolved imperceptibly into temporal lobe epilepsy, then complex partial seizures, and now limbic epilepsy. These terms are not synonymous but have been used interchangeably. Possibly there are limbic discharges in generalised seizures, which complicates the terminology and the issues further. Precise definition and measurement of psychopathology are also important to distinguish between personality disorders and other psychiatric states, as emphasised by Trimble and Perez. ${ }^{17}$ Secondly, there is often a sampling bias. The high frequency of temporal lobe epilepsy in adult clinics is not widely appreciated. Three major studies of the application of the International League Against Epilepsy seizure classification to adult neurological clinics in different countries suggest that up to three quarters of the patients have partial seizures. ${ }^{18}$ Most of these will have temporal lobe epilepsy. ${ }^{11}$ Finding a high incidence of temporal lobe epilepsy among psychiatric patients with epilepsy may not be of great importance since it may simply reflect the incidence of this type of epilepsy in adult clinics. Thirdly, the electroencephalographic findings have tended to confuse as much as to illuminate the subject. Many authors include temporal spiking in their diagnostic criteria, some include other (for example, slow wave) temporal phenomena, and others avoid using electroencephalographic criteria. It should not be forgotten that "all that spikes is not fits,"19 and that in some psychiatric disorders unassociated with epilepsy temporal spikes or slow activity have been noted..$^{20}$ The latter observation, however, has reinforced the search for the temporal lobe basis of the psychopathology associated with temporal lobe epilepsy.

Finally, though it is widely recognised that many factors contribute to psychological disorders in epilepsy ${ }^{21} 22$-including brain damage, long term drug treatment, and powerful psychosocial influences-such factors are frequently not controlled for in studies of temporal lobe epilepsy and psychopathology. This is especially true of anticonvulsant treatment. Patients with partial seizures are more difficult to treat than those with generalised seizures, ${ }^{23}{ }^{24}$ which is one reason why temporal lobe epilepsy is seen frequently in adult clinics. Rodin et $a l^{25}$ showed that such patients end up taking more drugs than those with other types of seizure. There is increasing evidence that such polytherapy has an adverse effect on mental function. ${ }^{212627}$

Much psychopathology in temporal lobe epilepsy may be due to the interaction of multiple factors. Patients with partial seizures, especially when this is associated with brain damage, tend to have more frequent attacks, take more drugs, and suffer more adverse psychosocial stresses than patients with generalised seizures. More effective treatment of epilepsy at the onset may be the way to prevent chronic poorly controlled epilepsy with its attendant risk of chronic psychopathology. ${ }^{24}$

\section{E H REYNOLDS}

Consultant Neurologist,

Maudsley and King's College Hospitals,

London SE5 9RS

${ }^{1}$ Guerrant J, Anderson WW, Fischer A, et al. Personality in epilepsy. Springfield: Thomas, 1962

${ }^{2}$ Hill D. Historical review. In: Reynolds EH, Trimble MR, eds. Epilepsy and psychiatry. Edinburgh: Churchill Livingstone, $1981: 1-11$.

${ }^{3}$ Morel BA. Traité des dégénérescences physiques, intellectuelles et morales de l'espèce humaine et des causes qui produisent ses variétés maladaptives. Vol 1. Paris: Baillière, 1857.

4 Lennox WG. Brain injury, drugs, and environment as causes of mental decay in epilepsy. Am $\mathcal{F}$ Psychiatry 1942;99:174-80.

${ }^{5}$ Pond D. Epidemiology of the psychiatric disorders of epilepsy. In: Reynolds EH, Trimble MR, eds. Epilepsy and psychiatry. Edinburgh: Churchill Livingstone, $1981: 27-32$.
B Graham P, Rutter M. Organic brain dysfunction and child psychiatric disorder. Br Med F 1968;iii:695-700.

' Gibbs EL, Gibbs FA, Fuster B. Psychomotor epilepsy. Archives of Neurology and Psychiatry 1948;60:331-9.

${ }^{8}$ Koella WP. The functions of the limbic system-evidence from animal experimentation. In: Koella WP, Trimble MR, eds. Temporal lobe epilepsy, mania, and schizophrenia and the limbic system. Basle: Karger, 1982:12-39. (Advances in biological psychiatry, vol 8.)

${ }^{9}$ Koella WP, Trimble MR, eds. Temporal lobe epilepsy, mania, and schizophrenia and the limbic system. Basle: Karger, 1982. (Advances in biological psychiatry, vol 8.)

${ }^{10}$ Reynolds EH, Trimble MR, eds. Epilepsy and psychiatry. Edinburgh: Churchill Livingstone, 1981.

1 Stevens JR. Risk factors for psychopathology in individuals with epilepsy. In: Koella WP, Trimble MR, eds. Temporal lobe epilepsy, mania, and schizophrenia and the limbic system. Basle: Karger, 1982:56-80. (Advances in biological psychiatry, vol 8.)

12 Bear DM, Fedio P. Quantitative analysis of interictal behavior in temporal lobe epilepsy. Arch Neurol 1977;34:454-67.

${ }^{13}$ Bear D, Levin K, Blumer D, Chetham D, Ryder J. Interictal behaviour in hospitalised temporal lobe epileptics: relationship to idiopathic psychiatric syndromes. F Neurol Neurosurg Psychiatry 1982;45:481-8.

${ }^{14}$ Mungas D. Interictal behavior abnormality in temporal lobe epilepsy. A specific syndrome or nonspecific psychopathology? Arch Gen Psychiatry 1982;39:108-11.

${ }^{15}$ Hermann BP, Riel P. Interictal personality and behavioral traits in temporal lobe and generalized epilepsy. Cortex $1981 ; 17: 125-8$.

${ }^{16}$ Currie S, Heathfield WG, Henson RA, Scott DF. Clinical course and prognosis of temporal lobe epilepsy. A survey of 666 patients. Brain $1971 ; 94: 173-90$.

17 Trimble MR, Perez MM. The phenomenology of the chronic psychoses of epilepsy. In: Koella WP, Trimble MR, eds. Temporal lobe epilepsy, mania, and schizophrenia and the limbic system. Basle: Karger, 1982: 98-105. (Advances in biological psychiatry, vol 8.)

${ }^{18}$ Alving J. Classification of the epilepsies. An investigation of 1,508 consecutive adult patients. Acta Neurol Scand 1978;58:205-12.

19 Stevens JR. All that spikes is not fits. In: Shagass C, Gershon S, Friedhoff AJ, eds. Psychopathology and brain dysfunction. New York: Raven Press, 1977:183-98.

${ }^{20}$ Hill D. EEG in episodic psychotic and psychopathic behaviour. A classification of data. Electroencephalogr Clin Neurophysiol 1952;4: 419-42.

${ }^{21}$ Reynolds EH. Biological factors in psychological disorders associated with epilepsy. In: Reynolds EH, Trimble MR, eds. Epilepsy and psychiatry. Edinburgh: Churchill Livingstone, $1981: 264-90$.

22 Pond D. Psychological aspects of epilepsy-the family. In : Reynolds EH, Trimble MR, eds. Epilepsy and psychiatry. Edinburgh: Churchill Lvingstone, $1981: 291-5$.

${ }^{23}$ Rodin EA. The prognosis of patients with epilepsy. Springfield: Thomas, 1968.

${ }^{24}$ Shorvon SD, Reynolds EH. Early prognosis of epilepsy. Br Med $\mathcal{F} 1982$; 285:1699-1701.

${ }^{25}$ Rodin EA, Katz M, Lennox K. Differences between patients with temporal lobe seizures and those with other forms of epileptic attacks. Epilepsia 1976;17:313-20.

${ }^{26}$ Trimble MR, Reynolds EH. Anticonvulsant drugs and mental symptoms. A review. Psychol Med 1976;6:169-78.

${ }^{27}$ Reynolds EH. The pharmacological management of epilepsy associated with psychological disorders. Br f Psychiatry 1982;141:549-57.

\section{Amniotic band syndrome}

Amniotic bands are an unusual and ill recognised cause of fetal malformation. ${ }^{1}$ Their exact incidence is unknown, but reported series suggest they occur in between one in 1200 and one in 15000 live births. ${ }^{2}$ Clustering of cases has been recorded. ${ }^{3}$ They are commoner in early pregnancy. ${ }^{4}$ The relation between the bands and the fetal malformations with which they are associated remains controversial.

Morphologically no real advance has been made since the pathological features were summarised by Ballantyne in $1902 . .^{5}$ He concluded that amniotic bands and adhesions occur in relation to the head, abdomen, and back of the fetus, between the fetus and the umbilical cord, and between one part of the fetus and another. They may be associated with malformation of the limbs. Bands may occur between one part of the amnion and 